\title{
Variability of the pullout strength of cancellous bone screws with cement augmentation
}

\author{
P. Procter ${ }^{\mathrm{a}, \mathrm{b}}$, P. Bennani ${ }^{\mathrm{b}}$, C.J. Brown ${ }^{\text {b, }}$, J. Arnoldi ${ }^{\text {c }}$, D.P. Pioletti ${ }^{\mathrm{d}}$, S. Larsson ${ }^{\mathrm{e}}$ \\ a Stryker Osteosynthesis, Selzach, Switzerland \\ b School of Engineering and Design, Brunel University, Uxbridge, UK \\ c Clinic of Plastic and Hand Surgery, University Hospital Bern, Bern, Switzerland \\ d Laboratory of Biomechanical Orthopedics, EPFL, Lausanne, Switzerland \\ e Department of Orthopaedics, Uppsala University Hospital, Uppsala, Sweden
}

\section{A R T I C L E I N F O}

\section{Article history:}

Received 4 July 2014

Accepted 2 March 2015

\section{Keywords:}

Cancellous bone

Bone screws

Pullout testing

Human cadaver

Finite element modelling

\begin{abstract}
A B S T R A C T
Background: Orthopaedic surgeons often face clinical situations where improved screw holding power in cancellous bone is needed. Injectable calcium phosphate cements are one option to enhance fixation.

Methods: Paired screw pullout tests were undertaken in which human cadaver bone was augmented with calcium phosphate cement. A finite element model was used to investigate sensitivity to screw positional placement. Findings: Statistical analysis of the data concluded that the pullout strength was generally increased by cement augmentation in the in vitro human cadaver tests. However, when comparing the individual paired samples there were surprising results with lower strength than anticipated after augmentation, in apparent contradiction to the generally expected conclusion. Investigation using the finite element model showed that these strength reductions could be accounted for by small screw positional changes. A change of $0.5 \mathrm{~mm}$ might result in predicted pullout force changes of up to $28 \%$.

Interpretation: Small changes in screw position might lead to significant changes in pullout strength sufficient to explain the lower than expected individual pullout values in augmented cancellous bone. Consequently whilst the addition of cement at a position of low strength would increase the pullout strength at that point, it might not reach the pullout strength of the un-augmented paired test site. However, the overall effect of cement augmentation produces a significant improvement at whatever point in the bone the screw is placed. The use of polymeric bone-substitute materials for tests may not reveal the natural variation encountered in tests using real bone structures.
\end{abstract}

(c) 2015 Elsevier Ltd. All rights reserved.

\section{Introduction}

Many orthopaedic surgeons report difficulties of fixing bone screws (e.g. Andersson et al., 2000 or Strømsøe, 2004), especially into poor quality cancellous bone of low apparent density-bone with low bone volume to total volume (BV/TV) ratios. Bone quality and quantity in patients presenting with fragility fractures are often variable (e.g. Berlemann and Schwarzenbach, 1997; Chen et al., 2009; Thiele et al., 2007), and control of screw fixation in a surgical situation is challenging.

The number of clinically reported screw failures is high especially in patients with poor bone quality. Hip fracture screw failure rates vary between 3\% and 5\% (Jesudason and Jeyem, 2006; Kim et al., 2001) while for proximal humeral fractures rates can vary between 15\% and 40\% (Singer et al., 1998; Cantlon and Egol, 2013). It has been suggested (Procter, 2013) that the total number of screw failures due to loosening

\footnotetext{
* Corresponding author at: School of Engineering and Design, Brunel University, Kingston Lane, Uxbridge UB8 3PH, UK

E-mail address: chris.brown@brunel.ac.uk (C.J. Brown).
}

and/or migration worldwide is at least one million annually, and while some failures will not have significant clinical consequences, some may need immediate and costly surgical revision. To overcome some of these difficulties, the use of cement for screw augmentation is often considered. The clinical evidence for cement augmentation is presented in a recent meta-analysis by Namdari et al. (2013). They concluded that "Augmentation of intertrochanteric femur fractures with polymethyl methacrylate or calcium-phosphate may provide benefits in terms of radiographic parameters and complication rates".

Screw pullout strength is often predicted using pullout tests from bone models such as Sawbones ${ }^{\mathrm{TM}}$ (Ramaswamy et al., 2010; Flahiff et al., 1995; Yánez et al., 2010; Augat et al., 2002; Brown et al., 2000; Schoenfeld et al., 2008; Patel et al., 2010), and tests reported by Asnis et al. (1996) suggest that good agreement is reached in porous foams of various densities. However Chapman et al. (1996) found the strength range for the tests in a homogenous Sawbones ${ }^{\mathrm{TM}}$ material and those data available for human bone differ considerably. Tests of screw pullout with cement augmentation are therefore even more difficult, as bonesubstitute materials with appropriate mechanical strength and stiffness 
properties are often porous but with closed pores (as recommended by ASTM F543-07e1, 2007), meaning that cement distribution is limited and unrealistic, and in consequence the increase in measured pullout strengths can be unrealistically low. There are grades of Sawbones ${ }^{\mathrm{TM}}$ with interconnected porosity. However the cement distribution is unrealistically large and measured pullout forces will be overstated. The use of real bone may therefore be preferred (Andreassen et al., 2004; Collinge et al., 2007; Eriksson et al., 2002; Hoshikawa et al., 2003; Larsson and Procter, 2011; Leung et al., 2006; Mader et al., 2003; McKoy and An, 2000; Renner et al., 2004; Verlaan et al., 2006), but the fundamental structure can lead to significant variability (Bayraktar et al., 2004; Keaveny et al., 1994; Rincon Kohli, 2003), particularly when it involves poor quality osteopenic or osteoporotic bone. Repeatability of results can be difficult. Seebeck et al. (2005) have shown that this variability exists in pullout of screws from human bone. The evaluation of fixation devices through testing in poor quality bone, either human or animal, therefore often requires a large number of specimens to achieve significance.

Orthopaedic practitioners have used injectable cement in a predrilled screw hole, back-filled with cement prior to screw insertion to increase pullout strength and improve "stability". It is generally regarded as beneficial in its use with both cancellous and cortical screws (Gefen, 2002; Gausepohl et al., 2001). Particularly, Larsson et al. (2012) have shown that bone augmentation using calcium phosphate cements in a lapine in vivo model gives significantly improved pullout strength. As a result it might be expected that augmentation with cement should always improve fixation, and consequently improve surgical outcome.

As additional evidence of augmented screw performance through the use of a particular calcium phosphate cement (Hydroset ${ }^{\circledR}$ ) in human bone, a series of human cadaver tests was carried out using ten paired femurs, correcting for local density as determined through CT scans. However, in the analysis of the results of pullout force normalised for density from these tests on human bone it became evident that a small number of anomalous results were present. Because of the unexpected results a further series of ten human cadaver tests, was undertaken. These again showed similar anomalous results.

This pullout strength data from tests using bone screws inserted into calcium phosphate cement in human femurs is presented below. Our hypothesis is that these variations could occur as a result of small changes of screw insertion position, and finite element models provide data on the consequent variability of pull out strength. The discussion demonstrates how this might explain the unexpected test data obtained.

\section{Methods}

Two methods are presented. First, the methodology for the human cadaver study is detailed. Secondly, a brief outline of a simplified finite element model used to demonstrate relative values of screw pullout is presented; fuller descriptions and validation methods are given elsewhere (Brown et al., 2013).

\subsection{Human cadaver study}

The distal parts of eleven human femurs (numbers 1 to 11) were dissected from cadavers that were previously fixed in a solution of $91 \%$ alcohol, $2 \%$ formaldehyde and $7 \%$ phenol, and were kept in a refrigerator at approximately $4{ }^{\circ} \mathrm{C}$. No precise identification of the bones was available but they were thought to be mostly from middle-aged donors who did not suffer from diseases such as osteoporosis or arthritis.

Two cylinders of $25 \mathrm{~mm}$ diameter and about $20 \mathrm{~mm}$ length were extracted from the condyle of each femur. A hollow mill placed on a power drill running at 400 r.p.m. was used to cut out the cylinders. The specimens were then separated from the bone with a manual saw. The specimens were taken on the anterior-lateral and on the anterior-medial side of the condyles and then put in hermetically closed tubes (standard laboratory Falcon tubes), identified by the sample references (ID) and then again stored in the refrigerator at approximately $4{ }^{\circ} \mathrm{C}$.

The accuracy of the bone mineral density measurements (BMD) made using a CT scanner (Densiscan1000, QCT, Scanco, Brüttisellen, Switzerland) was checked with a reference "phantom". The specimens were placed in the scanner within the Falcon tube. A special fixture made of polystyrene foam and a metal point was used to align the surface of the sample (cortical side) with the scan starting plan and to align the axis of the sample with the axis of the scanner. Seven slices, starting from the bone surface in the direction of the bone core, were scanned each $2 \mathrm{~mm}$. The mean density was then calculated in circles of about $6 \mathrm{~mm}$ diameter on the slices where the metal point was no longer visible. This procedure ensured a density measurement of the exact bone volume in which the screw was to be placed. The Falcon tubes containing the samples were then put back to the refrigerator at $4{ }^{\circ} \mathrm{C}$.

To place the screws and cement, the Falcon tube containing the specimens was plunged for about $1 \mathrm{~h}$ in a water container heated to $37^{\circ} \mathrm{C}$ (Fig. 1). The samples, which had reached the body temperature after that time, were then placed in a purpose-made fixture box (Fig. 1) and a hole of $2.5 \mathrm{~mm}$ diameter was drilled $10 \mathrm{~mm}$ deep at the same location and along the axis of the bone cylinder that had been scanned. The hole was then tapped $10 \mathrm{~mm}$ deep with the correct manufacturer-recommended tap for $4.0 \mathrm{~mm}$ screws. Finally, the specimens were placed back in the Falcon tubes and plunged in the $37^{\circ} \mathrm{C}$ bath.

The calcium phosphate cement (Hydroset巴, Stryker) packs were stored for about $1 \mathrm{~h}$ in the room where the bone augmentation procedure took place. The room temperature was set at $19{ }^{\circ} \mathrm{C}$. The bone/ screw samples, kept in the Falcon tubes, were taken out from the $37{ }^{\circ} \mathrm{C}$ warm bath just before augmentation. The Hydroset liquid was mixed with the powder for $45 \mathrm{~s}$. At $2 \mathrm{~min}$, the mixture was injected in the pre-drilled holes and at $3 \mathrm{~min}$ the screws (standard orthopaedic screws $4 \mathrm{~mm}$ diameter $\times 35 \mathrm{~mm}$ long) were inserted $10 \mathrm{~mm}$ deep. After that the specimens were again placed in the special fixture box and back into the Falcon tubes immediately after screwing, and then plunged in the $37^{\circ} \mathrm{C}$ bath for $4 \mathrm{~h}$. The specimen selection process for augmented or non-augmented was randomised. Where the bone sample of the pair was not augmented, the same procedure for screw placement and temperature control was followed-with the omission of cement injection. One randomly selected sample (numbered 2) was

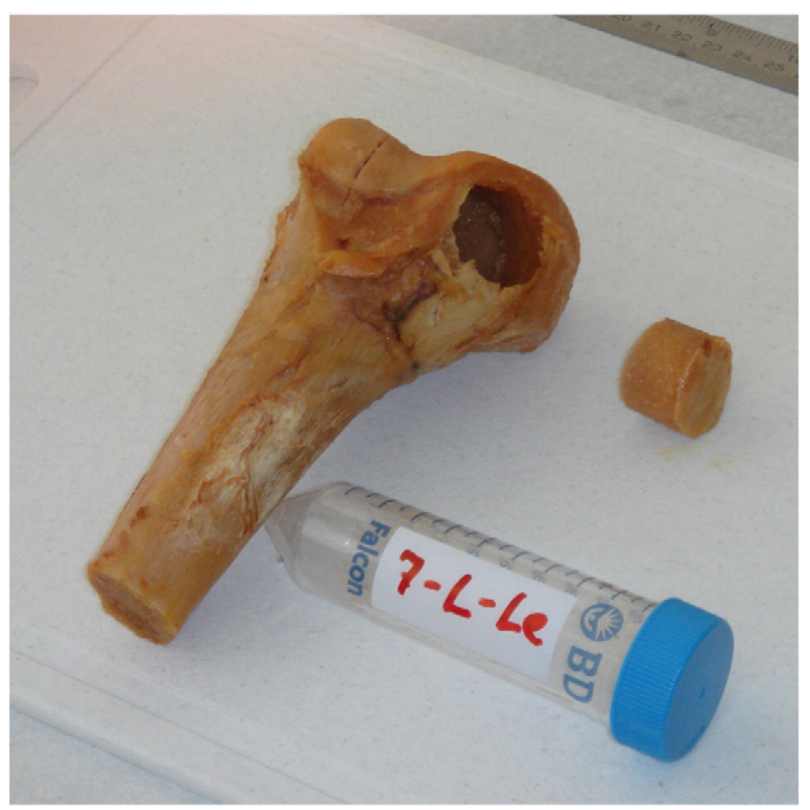

Fig. 1. Falcon tube and specimen. 
used to trial the protocol for both augmented and non-augmented screws.

After the 4-hour setting period, the head of the screw to be tested was placed through a $20 \mathrm{~mm}$ diameter hole in a $10 \mathrm{~mm}$ thick plate held in a fixture mounted on the test machine jack (see Fig. 2), and an axial displacement was applied at a rate of $5 \mathrm{~mm} / \mathrm{min}$, while the special fixture box with the bone cylinder was retained. The load and displacement were recorded, and the test was stopped after complete separation of the screw from the bone.

The complete protocol for these tests was subsequently carried out on a further set of ten samples, numbered from 12 to 21 .

\subsection{Finite element model}

The finite element model is a two-dimensional axisymmetric model, implemented using commercially available software. The geometric component has been generated to represent a regular grid of cancellous struts or trabeculae. The spacing of the struts is $1.0 \mathrm{~mm}$ (Fig. 3), while the trabecular strut thickness is $0.1 \mathrm{~mm}$. The use of an axisymmetric (2-D) model is a simplification that represents the cancellous bone as a series of regularly-spaced interconnected thin-walled annular tubes (Brown et al., 2013). Nevertheless, this gives a better approximation to cancellous bone structure than the alternative use of a continuum (Wirth et al., 2011), as it defines the connectivity between screw threads and the surrounding medium. The position of the screw relative

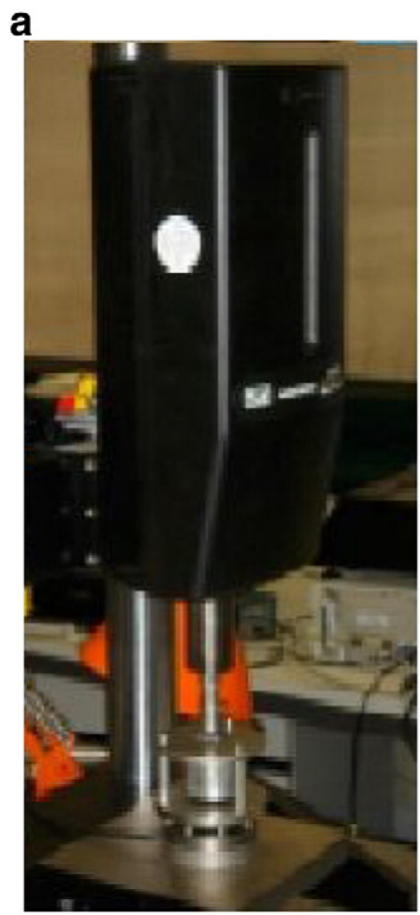

b

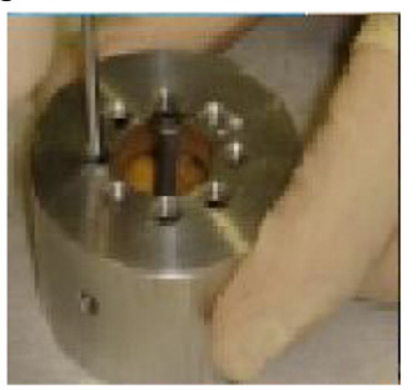

Fig. 2. Test rig (a) and specimen holder (b). to the bone surface can be moved both radially and along the axis of the screw.

One of the key elements of the model is that contact between the outer surface of the screw and the equivalent contacting (inner) surface of the bone is described by frictional contact elements, and because these surfaces are defined geometrically, sliding can occur. For the bone/cement interface, and the cement/screw interface it is assumed that full fixity occurs.

Values for the coefficient of friction between the bone and the screw have not been determined experimentally, but provided a value between about 0.35 and 0.7 is used, this variation has little effect (Hughes et al., 2014).

Material properties for the bone are taken from Rincon Kohli (2003) to give an elastic modulus of the bone elements of $2.2 \mathrm{GPa}$ and failure strength as $35 \mathrm{MPa}$, while the titanium screw has a modulus of $114 \mathrm{GPa}$-hence the relative stiffness of screw and bone is very high, and the screw is effectively a rigid body.

A bilinear strain hardening model was used, with a residual modulus of $1 \%$ (i.e. $22 \mathrm{MPa}$ ) used. The load displacement curves compare well to

a

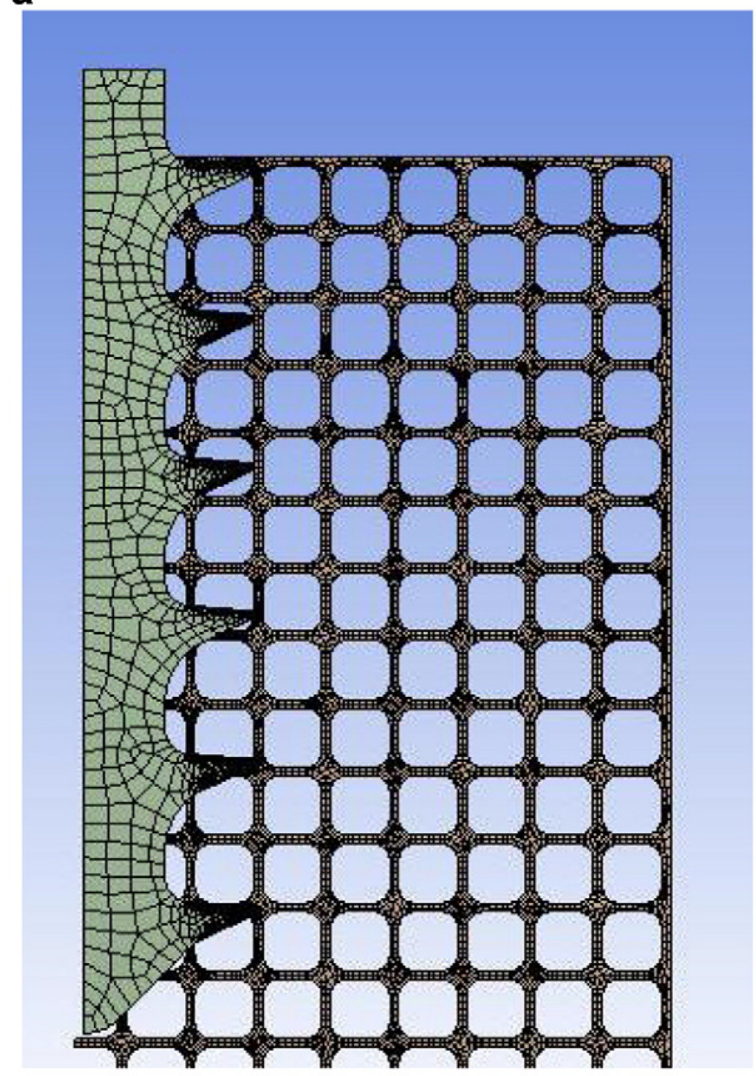

b

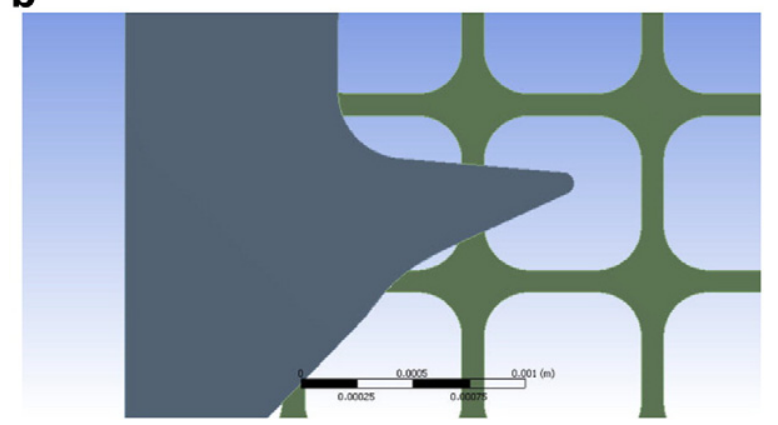

Fig. 3. Simplified finite element model showing mesh (a) and tooth engagement (b). 
Table 1

Pull-out forces per mm length of insertion.

\begin{tabular}{lcc}
\hline & Non-augmented & Augmented \\
\hline Mean pull-out force $(\mathrm{N})$ & 14.05 & 17.91 \\
Minimum pull-out force $(\mathrm{N})$ & 2.85 & 5.97 \\
Maximum pull-out force $(\mathrm{N})$ & 42.58 & 54.01 \\
Median pull-out force $(\mathrm{N})$ & 11.55 & 130.8
\end{tabular}

those given by Andrews EW Gibson (2001) who use a constant value of residual modulus of $25 \mathrm{MPa}$ for similar reasons of numerical stability. A similar failure criterion has also been used, where the slope of the loaddisplacement characteristic reduces to $95 \%$ of the elastic value.

The bone is restrained at the largest radius $(10 \mathrm{~mm})$, and pullout is achieved by the incremental displacement of the screw along its axis-the results presented being the reaction forces.

\section{Results}

Table 1 gives the values of pull-out force per mm. of insertion depth, while the pullout forces from the human cadaveric bone tested in vitro normalised for density are given in Fig. 4 (i.e. the actual values $/ 10 \mathrm{~mm}$ ). A typical load/displacement plot is shown in Fig. 5. The resulting values compare well with the values quoted by Seebeck et al. (2005) where for bones with small cortical thickness, pullout forces of the same order are given for a range of 4 bones tested.

Results demonstrate that the use of cement augmentation generally produces an increase in pullout strength. The ratio of pullout forces between the augmented and non-augmented specimen values is given in Fig. 6. The mean value of normalised pullout force for the $10 \mathrm{~mm}$ insertion length for the augmented specimens was $1091 \mathrm{Nmm}^{3} / \mathrm{g}$, while that for the non-augmented was $760 \mathrm{Nmm}^{3} / \mathrm{g}$ (median $776 \mathrm{Nmm}^{3} / \mathrm{g}$ c.f. $663 \mathrm{Nmm}^{3} / \mathrm{g}$, with $\max / \min 3858 / 369$ and 2028/430 $\mathrm{Nmm}^{3} / \mathrm{g}$ respectively, Fig. 7). The statistical comparison between the normalised pullout forces of the augmented and non-augmented specimens for each set of ten with the ANOVA Test showed a non-significant difference of $p<0.089$. However in two of the paired tests in the first series (shown circled as samples 7 and 11) the data indicate that the pullout strength in the augmented case is not increased over the pullout strength in the paired sample that is not augmented. The second cadaver study conducted using the same protocols shows again that two of the paired samples (samples 12 and 16 for the second series) produced the same trend in the results.

Nevertheless, the same unexpected result occurred in two of the samples in each series of tests, where the augmented test did not give sufficient strength increase to match the paired non-augmented test.

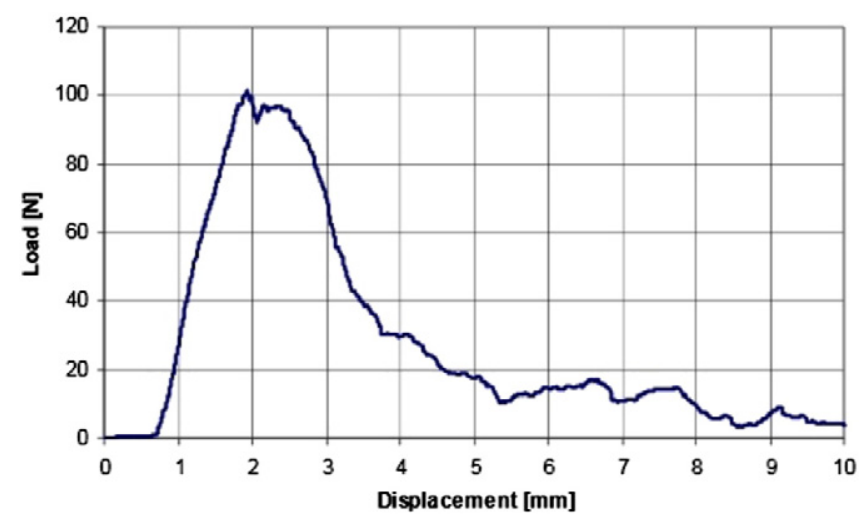

Fig. 5. Typical load/displacement plot.

The simplified finite element model compares the effect of different local bone stiffness, and in particular bone/screw interaction geometry. Using the FE model shows that as the interdigitation of screw thread and trabecular strut is changed, quite significant changes in pullout stiffness are observed. This simplified model is not intended to produce exact numerical similitude, and not to model the effect of cement (this has been presented elsewhere Brown et al., 2013) but to indicate the order of changes possible from small changes of position. For a given pullout displacement, the range of pullout force as the initial screw position in the bone is changed radially is shown in Fig. 8. Small changes in the position of the screw can lead to significant (up to about 28\%) changes in pullout stiffness. The force required to reach a specific displacement at which trabecular struts will fail is therefore also potentially subject to quite large variations.

\section{Discussion}

The experimental pullout test results show an anomaly. The nature of these results led to a re-examination of data already published (Larsson et al., 2012) for an in vivo animal study. This study has shown the general advantage of using calcium phosphate cement in screw augmentation in animals, but further analysis revealed individual results, at 1,5 and 10 days, that again contradicted the general result. In this study, a total of 4 out of the 14 results showed these counter-intuitive occurrences.

In general the pullout strength from the cadaver tests presented above is increased with the use of cement when the results are normalised for bone density. However a strength increase is not always present, and in two instances in each series of tests an individual result

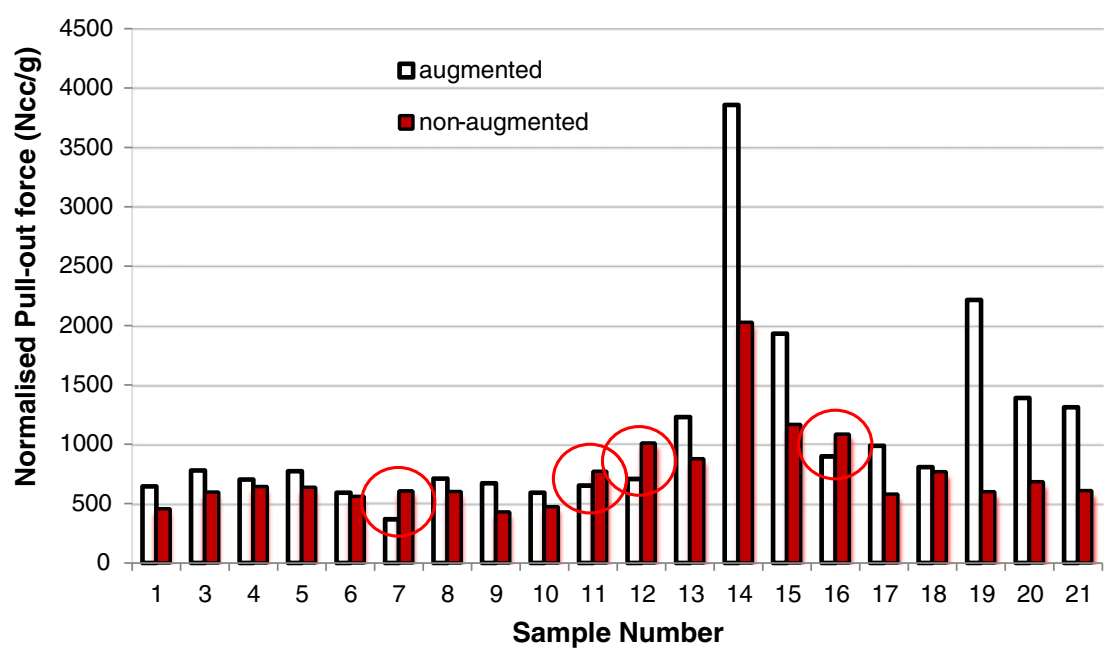

Fig. 4. Pullout force normalised for bone density. 


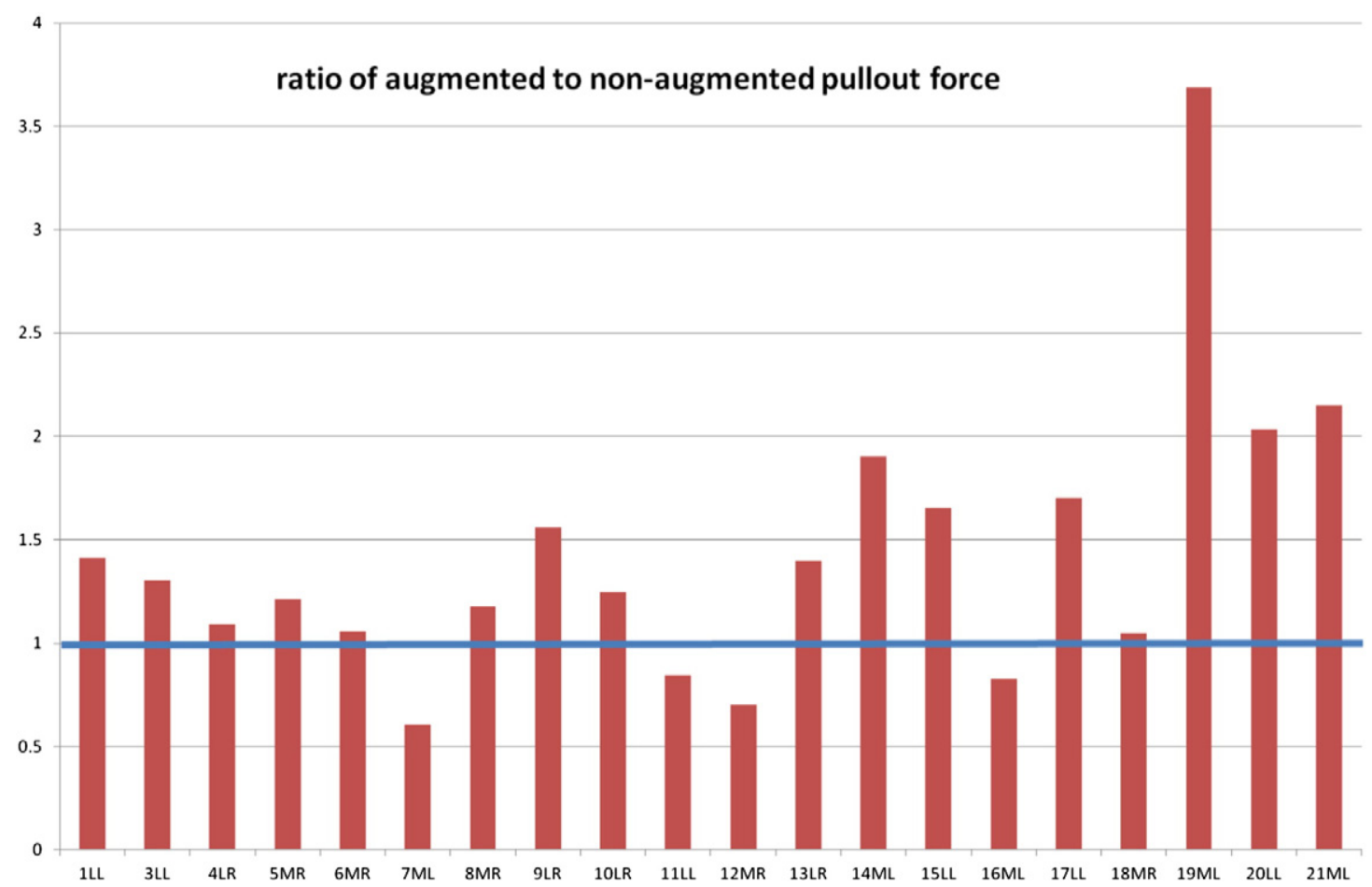

Fig. 6. Ratio of augmented to non-augmented normalised pullout force.

shows a decrease in strength. The two independent studies being done under strict identical protocols, it is then proposed that either the use of cement reduces the short-term pullout strength (which seems highly improbable from all we know), or there is some other factor that is dominant over the use of cement in the determination of pullout strength. It is widely accepted that pullout failure occurs through shear at the interface between bone and screw. Chapman et al. (1996) consider the key variables for the prediction of pullout forces from rigid foams are given by the equation:

$F_{S}=S \times A_{S}=S \times\left(L \times \pi \times D_{\text {major }}\right) \times T S F$

where: $F_{S}$ is the predicted shear failure force, $S$ is the material ultimate shear strength (stress), $A_{S}$ is the thread shear area, $L$ is the length of the screw, $\mathrm{D}_{\text {major }}$ is the major diameter of the screw, and TSF is a thread shape factor. Many authors (e.g. Bayraktar et al., 2004; Keaveny et al., 1994), agree that the strength of bone (tensile or shear) can be related to its overall apparent density through a power law relationship. Thus,

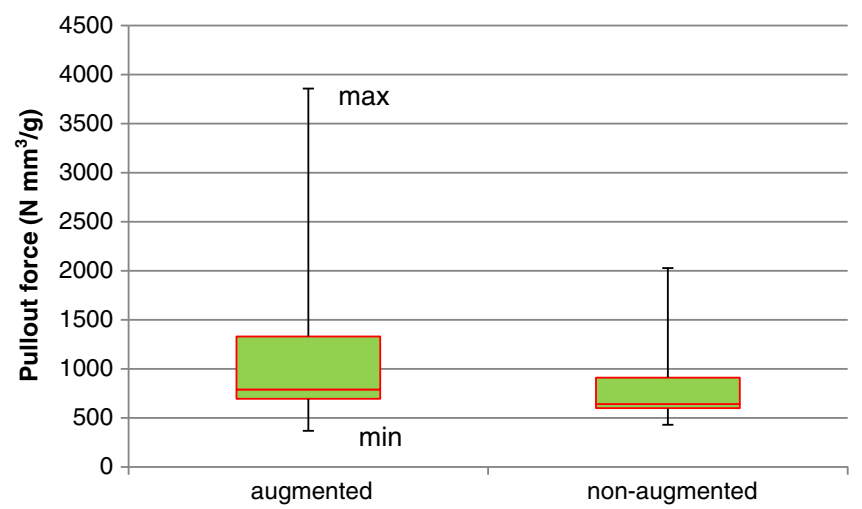

Fig. 7. Box plot of minimum, Q1, mean, Q3, and maximum. pullout strength should be strongly determined by bone quality, and results normalised for density should show good correlation. However, cancellous bone structures are cellular matrices (Gibson and Ashby, 1999) with quite distinct characteristics and, even in models, cannot be simplified to continua (Wirth et al., 2011). Gausepohl et al. (2001) have shown the effect of having small threads to produce better holding power in cancellous bone. In practice cancellous bone is open-pored and is potentially able to accept larger quantities of cement; however this may be limited in practice due to the presence of soft tissues within the cancellous structure. The importance of some of these parameters has been shown by Stadelmann et al. (2010). Ramaswamy et al. (2010) even suggest that "osteoporosis precludes screw purchase required for fracture fixation". It is therefore considered that the standard tests produce data that may not represent the in-service conditions that can be typical of a real bone fracture in a real patient.

In general, it is expected that screw augmentation (the phrase is widely used although in reality it is the intention to augment bone strength) by the addition of cement should significantly improve the pullout characteristics of screws from bone of any apparent density with either cancellous or cortical screws. Clinical application of cements in the USA is limited by FDA regulation to use as void fillers-not as screw augmentation products. In Europe cements can be used in cancellous bone for augmentation, and the assumption is that this will always improve holding power. A strength decrease is therefore an unexpected finding. The authors consider that it is unlikely that three entirely different tests would produce the same result without it having some factual basis.

The implication is that there is something about the construct that could potentially produce a less favourable outcome as a result of augmentation. The quality of the bone adjacent to the screw is very important. Using paired tests cannot entirely eliminate changes in modulus or strength of the bone, but the data revealed no significant changes to bone density, and hence no implied significant change in material properties. Alternative measurement of bone properties is not possible in tests to failure. However, FE data suggests that there is a high degree of sensitivity to positional placement of the screw. Fig. 8 shows that the magnitude of the difference in predicted pullout force for positions 


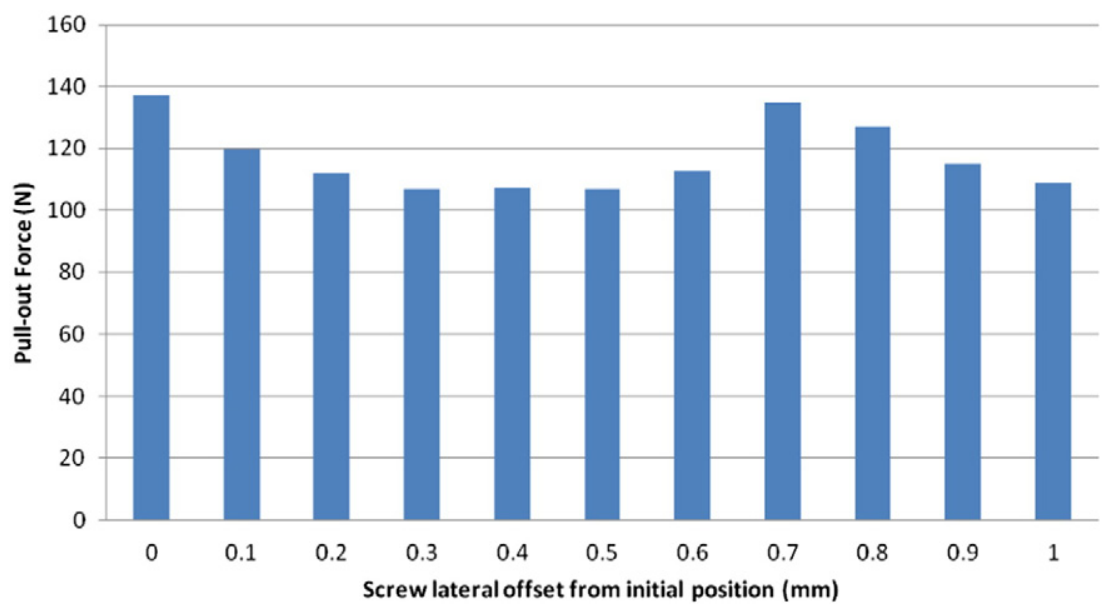

Fig. 8. Variation in pullout force with lateral position from FE model.

as close as $0.5 \mathrm{~mm}$ might be sufficient to account for significant changes in the pullout force.

If a screw is placed at a position where the pullout load is low (that might be significantly less than an immediately adjacent high strength position), then even a substantial increase due to augmentation might still result in a lower pullout load for that screw than its unaugmented pairing. It is therefore possible that the improvement of construct stiffness from augmentation might not cover the loss in stiffness from the small change in bone structure.

The effect of the cement does not come so much from the intrinsic properties of the cement itself, but is more as a result of stabilising the existing struts. From the authors' experience, tests in weak synthetic bone material will lead to failure at the interface between cement and un-augmented material. Fig. 9 shows two different bone profiles for the same screw. From left to right the figure shows the bone profile, the marked trabecular struts at that profile, the trabecular struts alone, and the way in which load can be transferred into the struts-indicated by the red arrow. In the first case, the load is carried at the tip of a trabecular strut, and a low load-carrying capacity will result. In the second case, the load is transferred into a trabecular strut that has significant support, and a higher load-carrying capacity will result.

The natural variation in real cancellous bone properties has often been considered an argument for adopting polymeric bone model test materials, as the variances associated with use of the latter are relatively
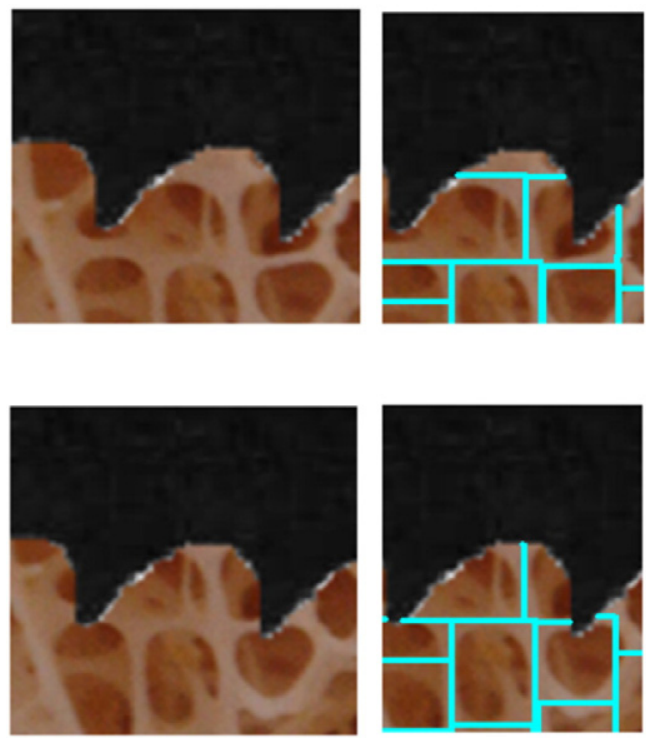

small. This study suggests that this might not necessarily be representative of real implant behaviour in real bone, and in particular such materials might significantly underestimate the coefficient of variation for device performance. In using polymeric materials the real variations from bone will not be observed.

\section{Conclusion}

Experiments on screw pullout from human cadaver bone reveal that the use of injectable cement-in this case injectable calcium phosphate cement-will generally increase the load required to achieve pullout. However, in each of the test series examined, a small number of results revealed an opposite trend. This is counter-intuitive.

Bone geometry and apparent density adjacent to the screw will change. The data presented indicate that there is a tremendous natural variation, significantly impacting the results from testing in real bone. This work has shown using models that, in the case of screw pullout, these effects might be large enough to mask the potential improvement effect from an augmentation product. In particular, the high sensitivity of pullout force to the position of the screw in the bone has been proposed. The current standards in orthopaedic screw design verification and validation of screws intended for use in fixation of cancellous bone do not readily take into account that such effects can be present in human bone.
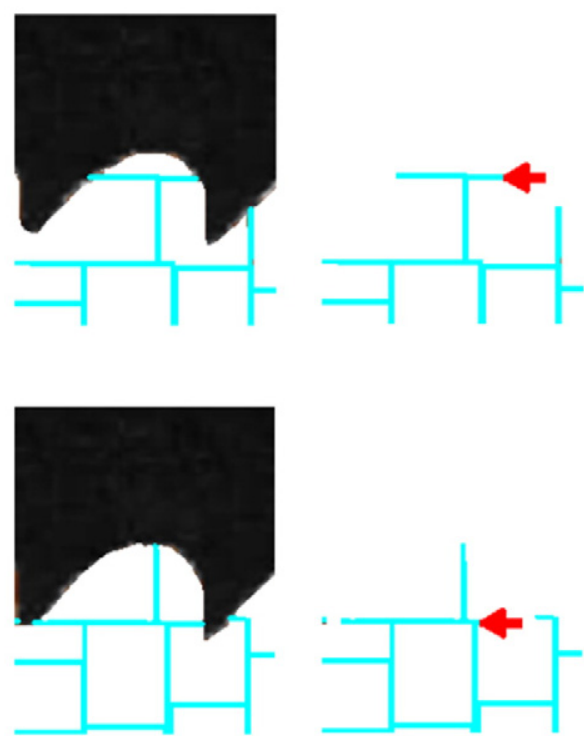

Fig. 9. Interdigitation model. 
Reassessment of published experimental data confirmed our findings. Even knowing about the natural variation within real bone, screw augmentation is still generally highly advantageous in clinical practice, and an appropriate use of cements can generally significantly increase the pullout forces of bone screws. The findings presented in this paper have caused the authors to initiate a further in-depth study to provide better understanding of the phenomena involved.

\section{Acknowledgements}

The authors gratefully acknowledge the contributions to the studies made by Dr V. Stadelmann (AOR, Davos, Switzerland) and Mr. M. Behrens (Stryker, Selzach, Switzerland). The experimental work was carried out at EPFL under the direction of Professor Pioletti and was funded by Stryker Trauma. At the time the work was carried out, Professor Procter and Dr Arnoldi were employed by Stryker Trauma. Dr Bennani's PhD studies at Brunel University were funded by Stryker Trauma AG.

\section{References}

Andersson, S., Rodrigues, M., Olerud, C., 2000. Odontoid fractures: high complication rate associated with anterior screw fixation in the elderly. Eur. Spine J. 9 (1), 56-59.

Andreassen, G.S., Hoiness, P.R., Skraamm, I., Granlund, O., Engebretsen, L., 2004. Use of a synthetic bone void filler to augment screws in osteopenic ankle fracture fixation. Arch. Orthop. Trauma Surg. 124, 161-165.

Andrews EW Gibson, L.J., 2001. The influence of cracks, notches and holes on the tensile strength of cellular solids. Acta Mater. 49, 2975-2979.

Asnis, S.E., Ernberg, J.J., Bostrom, M., Wright, T.M., Harrington, R.M., Tencer, A., Peterson, M., 1996. Cancellous bone screw thread design and holding power. J. Orthop. Trauma 10 (7), 462-469.

ASTM F543-07e1, 2007. Standard Specification and Test Methods for Metallic Medical Bone Screws.

Augat, P., Rapp, S., Claes, L., 2002. A modified hip screw incorporating injected cement for the fixation of osteoporotic trochanteric fractures. J. Orthop. Trauma 16 (5), 311-316.

Bayraktar, H.H., Morgan, E.F., Niebur, G.L., Morris, G.E., Wong, E.K., Keaveny, T.M., 2004 Comparison of elastic and yield properties of human femoral trabecular and cortical bone tissue. J. Biomech. 37, 27-35.

Berlemann, U., Schwarzenbach, O., 1997. Dens fractures in the elderly: results of anterior screw fixation in 19 elderly patients. Acta Orthop. 68 (4), 319-324.

Brown, G.A., McCarthy, T., Bourgeault, C.A., Callahan, D.J., 2000. Mechanical performance of standard and cannulated 4.0-mm cancellous bone screws. J. Orthop. Res. 18, 307-312.

Brown, C.J., MacInnes, R.A., Day, A., Hess, B., Procter, P., 2013. An approximate model for cancellous bone screw fixation. Comput. Methods Biomech. Biomed. Engin. 16 (4), 443-450 (March)

Cantlon, M.B., Egol, K.A., 2013. Calcium phosphate cement augmentation of proximal humerus fractures. Tech. Orthop. 28 (4), 302-307 (December).

Chapman, J.R., Harrington, R.M., Lee, K.M., Anderson, P.A., Tencer, A.F., Kowalski, D., 1996. Factors affecting the pullout strength of cancellous bone. J. Biomech. Eng. 118, 391-398 (August).

Chen, L.H., Tai, C.L., Lai, P.L., Lee, D.M., Tsai, T.T., Fu, T.S., Niu, C.C., Chen, W.J., 2009. Pullout strength for cannulated pedicle screws with bone cement augmentation in severely osteoporotic bone: influences of radial hole and pilot hole tapping. Clin. Biomech. 24 (9), 781-785.

Collinge, C., Merk, B., Lautenschlager, E.P., 2007. Mechanical evaluation of fracture fixation augmented with tricalcium phosphate bone cement in a porous osteoporotic cancellous bone model. J. Orthop. Trauma 21 (2), 124-128 (Feb).

Eriksson, F., Mattsson, P., Larsson, S., 2002. The effect of augmentation with resorbable or conventional bone cement on the holding strength for femoral neck fracture devices. J. Orthop. Trauma 16 (5), 302-310.

Flahiff, C.M., Gober, G.A., Nicholas, R.W., 1995. Pullout strength of fixation screws from polymethylmethacrylate bone cement. Biomaterials 16 (7), 533-536.

Gausepohl, T., Möhring, R., Pennig, D., Koebke, J., 2001. Fine thread versus coarse thread-a comparison of the maximum holding power Injury. Int. J. Care Injured 32, SD1-SD7.

Gefen, A., 2002. Optimizing the biomechanical compatibility of orthopedic screws for bone fracture fixation. Med. Eng. Phys. 24 (5), 337.
Gibson, L.J., Ashby, M.F., 1999. Cellular Solids: Structure and Properties. Edition 2. Cambridge University Press (revised).

Hoshikawa, N., Fukui, A., Fukuda, T., Sawamura, M., Hattori, K., Nakamura, H., Oda, H., 2003. Quantitative analysis of the resorption and osteoconduction process of a calcium phosphate cement and its mechanical effect for screw fixation. Biomaterials 24 , 4967-4975.

Hughes, C.M., Bordush, A., Robionek, B., Procter, P., Brown, C.J., 2014. Bone Anchors-A Preliminary Finite Element Study of Some Factors Affecting Pullout. ASME J. Med Devices http://dx.doi.org/10.1115/1 (March).

Jesudason, E.P., Jeyem, M., 2006. Failure of dynamic Hip screw (DHS) fixation for intertrochanteric fracture. Experience of a single district general hospital. J. Bone Joint Surg. (Br.) 88-B (Supp II), 250.

Keaveny, T.M., Wachtel, E.F., Ford, C.M., Hayes, W.C., 1994. Differences between the tensile and compressive strengths of bovine tibial trabecular bone depend on modulus J. Biomech. 27 (9), 1137-1146 (Sep).

Kim, W.Y., Han, C.H., Park, J.I., Kim, J.Y., 2001. Failure of intertrochanteric fracture fixation with a dynamic hip screw in relation to pre-operative fracture stability and osteoporosis. Int. Orthop. 25 (6), 360-362.

Larsson, S., Procter, P., 2011. Optimising implant anchorage (augmentation) during fixation of osteoporotic fractures: is there a role for bone-graft substitutes? Injury. Int. J. Care Injured 42, S72-S76.

Larsson, S., Stadelmann, V.A., Arnoldi, J., Behren, M., Hess, B., Procter, P., Murphy, M., Pioletti, D.P., 2012. Injectable calcium phosphate cement for augmentation around cancellous bone screws. In vivo biomechanical studies. J. Biomech. 45, 1156-1160.

Leung, K.S., Siu, W.S., Li, S.F., Qin, L., Cheung, W.H., Tam, K.F., Lui, P.P., 2006. An in vitro optimized injectable calcium phosphate cement for augmenting screw fixation in osteopenic goats. J. Biomed. Mater. Res. B Appl. Biomater. 78 (1), 153-160.

Mader, K., Pennig, D., Gausepohl, T., Patsalis, T., 2003. Calcaneotalotibial arthrodesis with a retrograde posterior-to-anterior locked nail as a salvage procedure for severe ankle pathology. J. Bone Joint Surg. Am. (Suppl. 4), 123-128.

McKoy, B.E., An, Y.H., 2000. An injectable cementing screw for fixation in osteoporotic bone. J. Biomed. Mater. Res. 53, 216-220.

Namdari, S., Rabinovich, R., Scolaro, J., Baldwin, K., Bhandari, M., Mehta, S., 2013. Absorbable and non-absorbable cement augmentation in fixation of intertrochanteric femur fractures: systematic review of the literature. Arch. Orthop. Trauma Surg. 133 (4) 487-494. http://dx.doi.org/10.1007/s00402-012-1677-2.Epub Jan 13 (Apr).

Patel, P.S.D., Shepherd, D.E.T., Hukins, D.W.L., 2010. The effect of screw insertion angle and thread type on the pullout strength of bone screws in normal and osteoporotic cancellous bone models. Med. Eng. Phys. 32, 822-828.

Procter, P., 2013. Designing an Augmentation System. GRIBOI, Boston.

Ramaswamy, R., Evans, S., Kosashvili, Y., 2010. Holding power of variable pitch screws in osteoporotic, osteopenic and normal bone: are all screws created equal? Injury 41 179-183.

Renner, S.M., Lim, T.-H., Kim, W.-J., Katolik, L., An, H.S., Andersson, G.B.J., 2004. Augmentation of pedicle screw fixation strength using an injectable calcium phosphate cement as a function of injection timing and method. Spine 29 (11), E212-E216.

Rincon Kohli, L, 2003. Identification of a multiaxial failure criterion for human trabecular bone. Faculté Sciences et Technique de l'Ingénieur, Institut de genie biomedical section de genie mécanique, Lausanne, Switzerland, Ecole polytechnique Federale de Lausanne. PhD Thesis.

Schoenfeld, A.J., Battula, S., Sahai, V., Vrabec, G.A., Corman, S., Burton, L., Njus, G.O., 2008 Pullout strength and load to failure properties of self-tapping cortical screws in synthetic and cadaveric environments representative of healthy and osteoporotic bone J. Trauma 64, 1302-1307.

Seebeck, J., Goldhahn, J., Morlock, M.M., Schneider, E., 2005. Mechanical behavior of screws in normal and osteoporotic bone. Osteoporos. Int. 16, S107-S111.

Singer, B.R., McLauchlan, G.J., Robinson, C.M., Christie, J., 1998. Epidemiology of fractures in 15,000 adults-the influence of age and gender. J Bone Joint Surg. Mar. 80 (2), 243-248.

Stadelmann, V.A., Bretton, E., Terrier, A., Procter, P., Pioletti, D.P., 2010. Calcium phosphate cement augmentation of cancellous bone screws can compensate for the absence of cortical fixation. J. Biomech. 43 (15), 2869-2874.

Strømsøe, K., 2004. Fracture fixation problems in osteoporosis, Injury. Int. J. Care Injured $35,107-113$.

Thiele, O.C., Echhardt, C., Linke, B., Schneider, E., 2007. Factors affecting the stability of screws in human cortical osteoporotic bone. JBJS 89-B (5), 701-705.

Verlaan, J.-J., Oner, F.C., Dhert, W.J.A., 2006. Anterior spinal column augmentation with injectable bone cements. Biomaterials 27, 290-301.

Wirth, A.J., Muller, R., van Lenthe, G.H., 2011. The discrete nature of trabecular bone microarchitecture affects implant stability. J. Biomech. 12.024.

Yánez, A., Carta, J.A., Garcés, G., 2010. Biomechanical evaluation of a new system to improve screw fixation in osteoporotic bones. Med. Eng. Phys. 32, 532-541. 